\title{
Photocoagulation-Induced Retinal Gliosis Is Inhibited by Systemically Expressed Soluble TGF- $\beta$ Receptor Type II via Adenovirus Mediated Gene Transfer
}

\author{
Toshio Hisatomi, Taiji Sakamoto, Ichiro Yamanaka, Yukio Sassa, Toshiaki Kubota, \\ Hikaru Ueno, Yoshitaka Ohnishi, and Tatsuro Ishibashi
}

Department of Ophthalmology (TH, TS, IY, YS, TK, TI), Graduate School of Medical Sciences, Kyushu University, Fukuoka; Department (HU) of Biochemistry, University of Occupational and Environmental Health, Kitakyushu; and Department of Ophthalmology (YO), Wakayama Medical College, Wakayama, Japan

\begin{abstract}
SUMMARY: Retinal gliosis is one of the major causes of visual dysfunction due to the loss of the retinal regular structure and function in various diseases, including diabetic retinopathy, retinal detachment, and glaucoma. Transforming growth factor- $\beta$ (TGF- $\beta$ ) is assumed to play an important role in this disease process. In the present study, we determined whether the systemically expressed extracellular domain of the TGF- $\beta$ type II receptor by adenovirus-mediated gene delivery could inhibit experimental retinal gliosis both in vitro and in vivo. Cultured bovine retinal glial cells, Müller cells, were stimulated by recombinant TGF- $\beta$ and the expression of the glial marker, glial fibrillary acidic protein (GFAP), was evaluated by immunohistochemistry, semiquantitative RT-PCR, and Western blotting. In cultured Müller cells, TGF- $\beta$ stimulated the GFAP expression in a dose-dependent fashion, and the conditioned medium from 293 cells transfected with adenovirus encoding for a soluble form TGF- $\beta$ type II receptor (AdT $\beta$-ExR) inhibited the expression of GFAP stimulated by exogenous TGF- $\beta(p<0.05)$. In this process, Smad4 protein, which plays a key role in intracellular signaling after cell surface receptors, actually translocated from cytosol to nucleus with TGF- $\beta$ stimulation. The conditioned medium from AdT $\beta$-ExR also inhibited the cytosol-nuclear translocation of Smad4. For in vivo studies, AdT $\beta$-ExR was injected into the femoral muscles of Brown Norway rats and retinal photocoagulation was subsequently carried out. Immunohistochemical studies revealed that GFAP was strongly expressed around the photocoagulation spots after 12 days and these phenomena were inhibited by AdT $\beta$-ExR. Western blotting of total retinal extract demonstrated the same results as those observed after immunohistochemistry. Our results suggest that TGF- $\beta$ plays a pivotal role in the pathologic processes in retinal gliosis, and that the systemically expressed soluble TGF receptor by gene delivery may thus have a potential therapeutic value by inhibiting excessive retinal gliosis in various ocular diseases. (Lab Invest 2002, 82:863870).
\end{abstract}

$G$ liosis is frequently found in various pathologic of the glial cells in the damaged area of neural tissues. Glial cells are found ubiquitously throughout the central nervous system (CNS) and become activated and undergo reactive gliosis when neuronal damage occurs. Although glial cells are important for the protection or repair of neurons, their activation is sometimes harmful under certain circumstances and thus contributes to disease progression (Ridet et al, 1997; Streit et

\section{DOI: 10.1097/01.LAB.0000018829.49754.DD}

Received January 16, 2002.

This work was supported in part by grant-in-Aid 09671804 and 09307040 for Scientific Research from the Ministry of Education, Science, Sports, and Culture of the Japanese Government, the Japan National Society for the Prevention of Blindness (Tokyo), the Fukuoka Anti-Cancer Association (Fukuoka), the Kaibara Morikazu Medical Science Promotion Foundation (Fukuoka), and the Casio Science Promotion Foundation (Tokyo).

Address reprint requests to: Dr. Toshio Hisatomi, Department of Ophthalmology, Graduate School of Medical Sciences, Kyushu University, 3-1-1 Maidashi, Higashi-ku, Fukuoka, 812-8582, Japan. E-mail: hisatomi@med.kyushu-u.ac.jp al, 1999). In ocular tissue, retinal gliosis is also found in various pathologies, such as diabetic retinopathy, retinal detachment, and glaucoma (Dyer and Cepko, 2000; Hisatomi et al, 2001; Ikeda et al, 1998) and excessive retinal gliosis also impairs the vision of individuals. The rapid up-regulation of intermediate filament production develops in this process, and glial fibrillary acidic protein (GFAP) is an established marker for the reactive gliosis (Dyer and Cepko, 2000; Taomoto et al, 1998). The expression of GFAP is regulated by a wide variety of cytokines and growth factors. Among of them, transforming growth factor- $\beta$ (TGF- $\beta$ ) is supposed to play an important role in this process (Laping et al, 1994; Reilly et al, 1998).

TGF- $\beta$ s are widely recognized as multifunctional growth factors and the key regulators of biologic processes. The major functions of TGF- $\beta$ s are the control of cell proliferation and differentiation, such as fibrosis and gliosis (da Cunha et al, 1993; Lippa et al, 1995). TGF- $\beta$ s have been isolated and divided into five isoforms; TGF- $\beta 1,-\beta 2$, and $-\beta 3$ are expressed in mammalian tissues. Comprehensive studies have been conducted on the widespread distribution of TGF- $\beta$ s in the developing and adult CNS and the 
peripheral nervous system (PNS) (Bottner et al, 2000; Flanders et al, 1991; Unsicker, 2000). The consistent coexpression of TGF- $\beta$ s has been shown in neurons, astroglial, and Schwann cells. Ocular studies of TGF- $\beta$ s has shown the expression of TGF- $\beta$ s in the neural retina, retinal pigment epithelium, hyalocytes, and choroid (Anderson et al, 1995; Pfeffer et al, 1994).

Cross-linking studies have revealed that TGF- $\beta$ s bind to several cell-surface proteins, termed type I, type II, and type III receptors, wherein receptors type I and II are responsible for intracellular signal transduction. Receptor I has been shown to require receptor II for ligand binding, whereas receptor I and the kinase activity of receptor II are required for signaling. In addition to these cell-surface serine/threonine kinase receptors, Smad proteins play a key role in the intracellular signaling (Nakao et al, 1997). The type II receptor recruits and phosphorylates type I receptor, which then phosphorylates Smad2 and Smad3. The phosphorylated Smads form complexes with Smad4 and translocate from cytosol to the nucleus, which results in the activation of target genes with transcription factors, coactivators, and corepressors.

A large obstacle in investigating the role of TGF- $\beta$ in vivo is a lack of any suitable methods to specifically inhibit the TGF- $\beta$ action. TGF- $\beta 1-$ and $-\beta 2-$ deficient mice have been developed by gene targeting, but they usually die by 3 to 4 weeks of age. To block TGF- $\beta$ signaling in a TGF- $\beta$-specific manner, we constructed adenoviral vectors expressing a dominant negative TGF- $\beta$ receptor type II of truncated (AdT $\beta$-TR) and soluble (AdT $\beta$-ExR) form. This truncated type receptor inhibits TGF- $\beta$ binding to wild-type receptor competitively, resulting in blocking TGF- $\beta$ signaling of the infected cells (Qi et al, 1999). The soluble type recêptor is secreted from the infected cells, and inhibits TGF signaling in vitro. In our previous studies, we confirmed that the adenovirus injected in skeletal muscle produced a soluble receptor, and this soluble receptor was thereafter redistributed into the eyes by the normal blood circulation (Sakamoto et al, 2000).

In the present study, we inhibited retinal gliosis by blocking TGF- $\beta$ signaling using two different adenovirus vectors, AdT $\beta$-TR and AdT $\beta$-ExR. We have shown that TGF- $\beta$ plays a pivotal role in the pathologic processes in retinal gliosis, and that an inhibition of excessive retinal gliosis helped to maintain the retinal regular structure after retinal photocoagulation $(\mathrm{PC})$ in an animal model of neural gliosis.

\section{Results}

\section{GFAP Expression in Cultured Bovine Müller Cells}

The conditioned medium from 293 E1 cells infected with the adenoviral vector, AdT $\beta$-ExR, expressing an entire extracellular domain of TGF- $\beta$ receptor type II and AdLacZ-expressing $\beta$-galactosidase, was prepared and used in the following studies. Cultured bovine retinal glial cells, Müller cells, expressed GFAP protein in a dose-dependent manner by TGF- $\beta$ stimulation (Fig. 1) and the expression peaked 12 hours

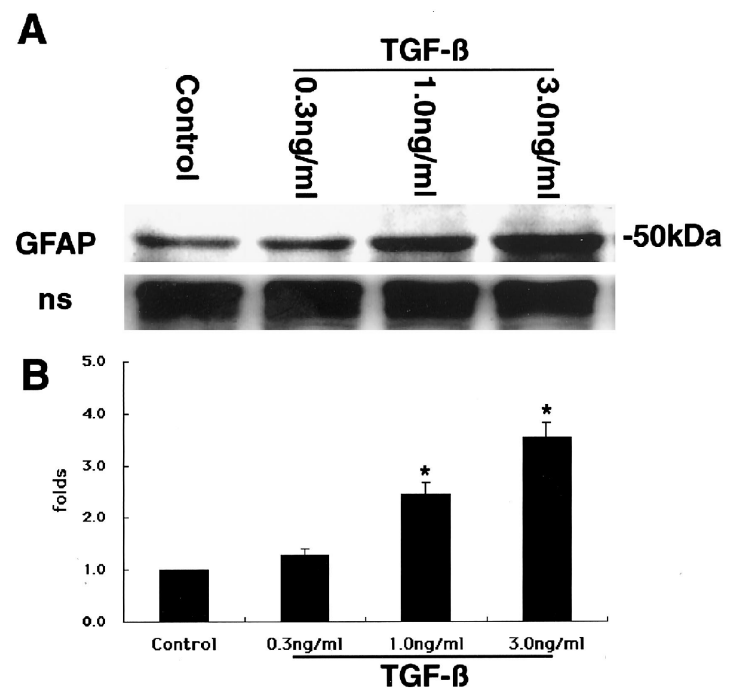

Figure 1.

Glial fibrillary acidic protein (GFAP) expression stimulated by recombinant transforming growth factor- $\beta$ (TGF- $\beta$ ) in cultured Müller cells. A, Weak GFAP expression is observed without stimulation (control). TGF- $\beta$ increased GFAP expression in a dose-dependent manner. Nonspecific staining is shown as a lane loading control. B, Semiquantitative data were generated by scanning film exposures of the gel using a densitometer. Three independent examinations were made and the results are expressed as the "fold" increase over the control GFAP expression (mean $\pm \mathrm{sD} ;{ }^{*} p<0.05$ ).

after stimulation (data not shown). The GFAP expression was suppressed by the conditioned medium containing dominant-negative soluble TGF- $\beta$ receptor type II (AdT $\beta$-ExR; Fig. 2). Cultured Müller cells showed low expression of GFAP without TGF stimu-
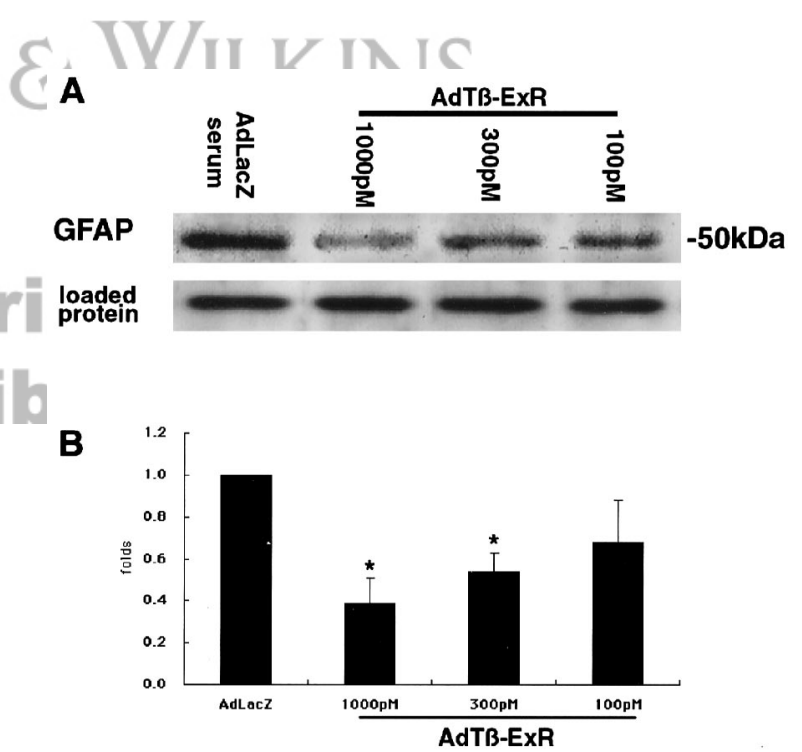

Figure 2.

Effect of TGF- $\beta$ type II soluble receptor on GFAP expression stimulated by TGF- $\beta$. A, The conditioned medium from $293 \mathrm{E} 1$ cells infected with AdLacZ or AdT $\beta$-ExR was administered in cultured Müller cells. The conditioned medium from AdT $\beta$-ExR suppresses GFAP expression in a dose-dependent fashion, whereas the conditioned medium from AdLacZ shows no remarkable changes. $B$, Semiquantitative data were generated by scanning film exposures of the gel using a densitometer. Three independent examinations were made and the results are expressed as a "fold" increase over the control GFAP expression (mean $\left.\pm \mathrm{SD} ;{ }^{*} p<0.05\right)$. 
lation (Fig. 1). Cultured Müller cells also showed upregulation of GFAP mRNA after 30 minutes after TGF- $\beta$ stimulation, the expression peaked 4 hours after stimulation, and the expression reduced gradually (not shown). In the same way, the GFAP mRNA up-regulation was dose-dependent with TGF- $\beta$ concentration used in this study (Fig. 3). Cultured Müller cells showed low expression of GFAP mRNA without stimulation (Fig. 3). This mRNA up-regulation stimulated by TGF- $\beta$ was also blocked by the conditioned medium from AdT $\beta$-ExR containing the soluble receptor, and the blocking effect was in a dose-dependent manner, whereas AdLacZ did not block the GFAP mRNA up-regulation (Fig. 4).

\section{Nuclear Translocation of Smad4 by TGF- $\beta$}

To obtain insight into the cellular and molecular events of cell-surface receptors of TGF- $\beta$, immunostaining using anti-Smad 4 antibody was performed. In cultured GFAP-positive Müller cells (Fig. 5, A to C), Smad4 protein distributed diffusely in the cytosol (Fig. 5, D to $\mathrm{F})$, but translocated into the nucleus after 30 minutes of TGF- $\beta$ stimulation ( $3.0 \mathrm{ng} / \mathrm{ml}$, Fig. 5 , G to 1$)$. The conditioned medium containing the soluble TGF- $\beta$ receptor type II effectively inhibited the Smad4 nuclear translocation (Fig. 5, J to L). The control medium from the $293 \mathrm{E} 1$ cells infected with adenovirus (AdLacZ) did not significantly change the patterns of either the regular localization of Smad4 protein in the cytosol or the nuclear translocation of Smad4 that occurred after the stimulation (not shown).

A

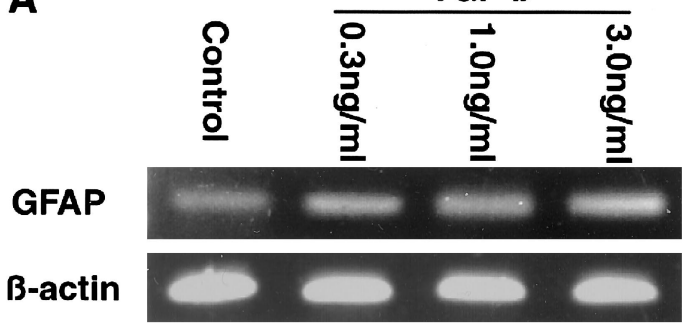

B

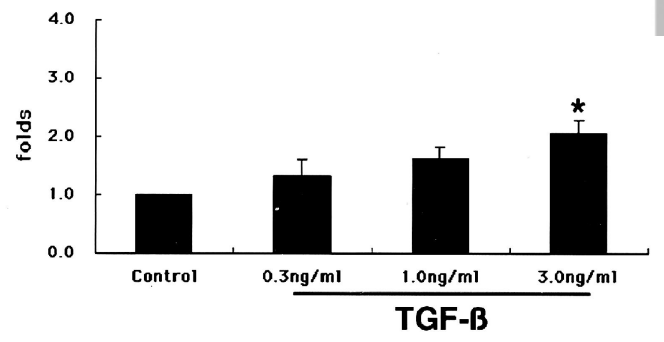

Figure 3.

Effect of TGF- $\beta$ on GFAP mRNA expression in cultured Müller cells. A, RT-PCR analysis with primers specific for GFAP (upper level) or $\beta$-actin (lower level) of RNA isolated from cultured Müller cells. Faint GFAP mRNA is expressed in Müller cells without stimulation. TGF- $\beta$ stimulates mRNA expression in a dose-dependent manner. mRNA of GFAP was normalized by that $\beta$-actin and the ratio to the data is presented. The representative data of three experiments is presented. B, Semiquantitative data were generated by scanning film exposures of the gel using a densitometer. Three independent examinations were made and the results are expressed as a "fold" increase over the control GFAP mRNA expression (mean $\pm \mathrm{SD} ;{ }^{\star} p<0.05$ ).
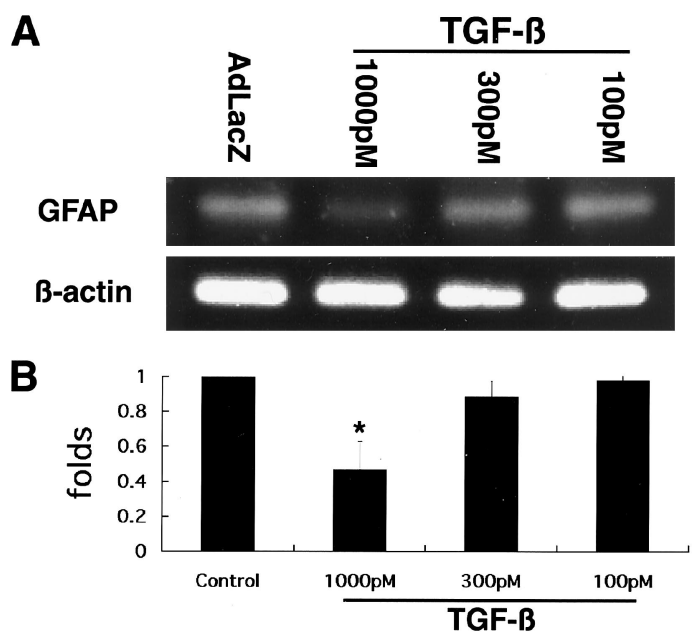

Figure 4.

Effect of TGF- $\beta$ type II soluble receptor on GFAP mRNA expression stimulated by TGF- $\beta$. A, The conditioned medium form AdT $\beta$-ExR suppresses GFAP mRNA expression in the same manner shown in the protein level, whereas the medium from AdLacZ does not (Fig. 2). B, Three independent examinations were made and the results are expressed as a "fold" increase over the control GFAP mRNA expression (mean $\pm \mathrm{sD} ;{ }^{*} p<0.05$ ).

\section{Retinal Gliosis in an Animal Model of Photocoagulation}

Histopathologically, retinas with PC showed retinal degeneration and gliosis around the PC spots (Fig. 6). Some retinal pigment epithelial cells migrated into the degenerated retina. Subretinal proliferation was also observed around the PC spots, but the subretinal proliferation was clearly distinguishable from retinal gliosis.

Immunohistochemistry of the extradomain of TGF- $\beta$ receptor type II showed positive staining mainly in the ganglion cell layer, inner plexiform layer, inner nuclear layer, and outer nuclear layer around the PC spots. Although administration of AdLacZ showed no remarkable changes in the staining pattern of TGF- $\beta$ receptor (Fig. 6A), AdT $\beta$-TR showed a remarkable expression of the receptor mainly in the inner layer of the transfected retina (Fig. 6B). Additionally, AdT $\beta$ ExR showed an overexpression of the receptor in the outer layer of the retina (Fig. 6C). The tagged Fc portion of human IgG expression was only seen in the AdT $\beta$-ExR group (Fig. 6, D to F). The tagged protein expression showed diffuse localization in all retinal layers, especially around PC spots, indicating a localization of overexpressed soluble TGF- $\beta$ receptor type II (Fig. 6F).

Immunohistochemistry for the glial marker GFAP revealed a strong expression around the PC spots of the AdLacZ-injected eyes (Fig. 6G). Although Müller cells were located vertically in all retinal layers, their cytosol or footplates were located in the inner and outer layers of the retina, and positive staining of GFAP was strongly observed in the inner and outer retinal layers. Both retinal gliosis and the GFAP expression decreased by AdT $\beta$-TR intravitreous injection and AdT $\beta$-ExR intramuscular injection (Fig. 6, G to I). Western blotting with total retinal extract also showed that PC up-regulated the GFAP expression, 

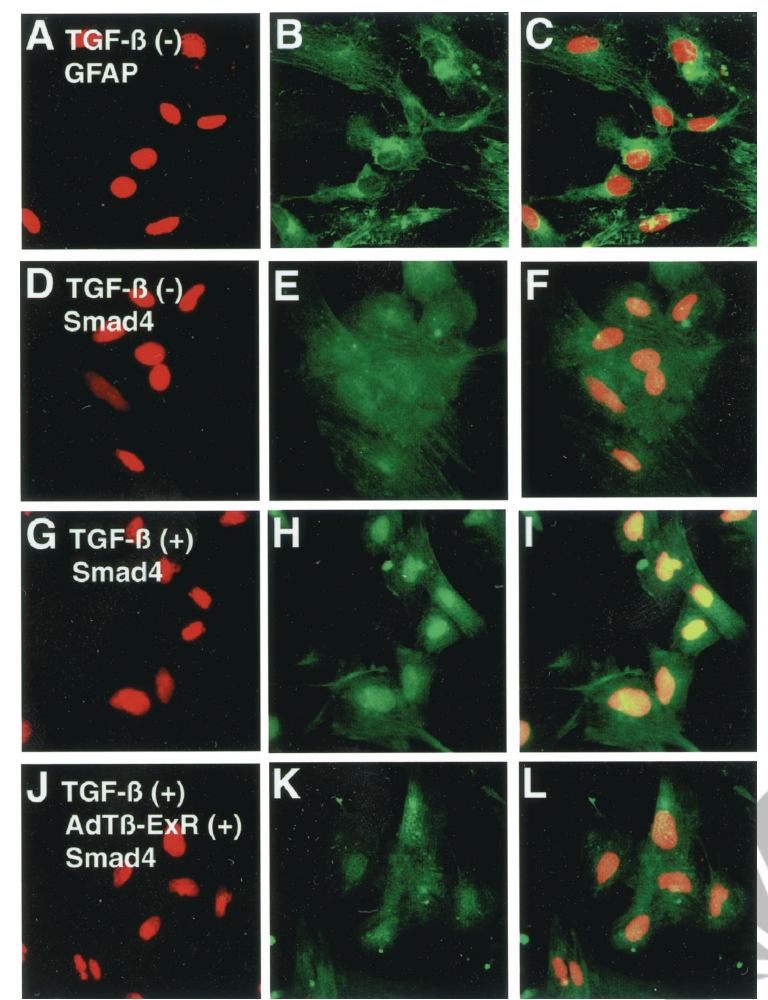

Figure 5.

Immunohistochemistry of GFAP and Smad4 in cultured Müller cells. GFAP staining is seen in Müller cells (B and $C$, green). Cell nuclei are stained with propidium iodide (red). Smad4 staining of the three groups (TGF- $\beta(-)$, TGF- $\beta$ $(+)$, and TGF- $\beta(+) /$ AdT $\beta$-ExR) is shown in D to L. Although Smad4 staining is positive in cytosol without TGF- $\beta$ stimulation ( $E$ and F), they become translocated in the nucleus after TGF- $\beta$ stimulation ( $(H$ and I ). These translocation are suppressed by the conditioned medium from AdT $\beta$-ExR (K and $\mathrm{L}$ ). (Original magnification, $\times 400$.)

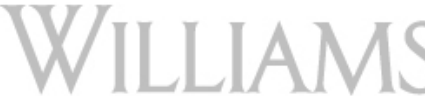

whereas AdT $\beta$-TR and AdT $\beta$-ExR significantly suppressed the expression on Day 12 (Fig. 7), in the same manner as that shown histopathologically.

\section{Discussion}

In the present study, we have shown that TGF- $\beta$ soluble type II receptor by adenovirus-mediated gene transfer effectively inhibited TGF- $\beta$ signaling and retinal gliosis both in vitro and in vivo. TGF- $\beta$ thus plays a pivotal role in the pathologic processes of retinal gliosis, and the inhibition of retinal gliosis shown in the present method helped to maintain the retinal regular structure after retinal PC.

We used retinal PC to cause the same degree of retinal injury reproducibly with a minimal degree of either surgical trauma or inflammation. Retinal PC is often used in well-established experimental models of choroidal neovascularization. In our model, PC was not strong enough to significantly induce retinal neovascularization. Subretinal proliferation was sometimes observed around PC spots, but such subretinal proliferation was clearly distinguishable from retinal gliosis (Fig. 6). Immunohistochemistry revealed the entire damaged retinal area to be positive for the glial cell marker GFAP (Fig. 6). By Western blotting of the total retinal extract, the GFAP protein was upregulated significantly after $\mathrm{PC}$, which correlated with the expression of GFAP and retinal gliosis as found histopathologically. The present method is thus considered to be suitable as an animal model of neural gliosis.

The inhibition of excessive gliosis in neural tissue remains an important problem. There have been numerous studies on this subject, including investigations regarding the suppression of astrocyte structural proteins, ablation of astrocytes, attenuation of factors stimulating astrogliosis, genetic modification of extracellular matrix (ECM) (Audouy et al, 1999; Dyer and Cepko, 2000). Audouy et al (1999) reported adenovirusmediated suicide gene therapy in glial cells in vitro. In the present study, we attempted to inhibit retinal gliosis by blocking TGF- $\beta$ signaling, because TGF- $\beta$ is richly produced in the injured retina and TGF- $\beta$ is the strong initiator of fibrosis in wound healing processes (Ishida et al, 1998; Ogata et al, 1997; Yamamoto et al, 1998). In addition, Logan et al $(1994,1999)$ showed TGF- $\beta$ antibodies to be potentially applicable to CNS disorders in vivo.

We blocked the TGF- $\beta$ signaling of retinal glial cells by the adenovirus-mediated gene delivery of soluble TGF- $\beta$ receptor type II from a remote organ. In our previous studies, using the same system, the soluble TGF- $\beta$ receptor type II was detected in ocular fluid at a concentration of $2.3 \times 1,000$ pM on Day 5 (Sakamoto et al, 2000). This concentration was sufficiently high to block GFAP up-regulation in cultured Müller cells in vitro (1,000 pM). In the present study, the intramuscular injection of AdT $\beta$-ExR caused the systemic expression of soluble TGF- $\beta$ receptor, and the soluble receptor distributed in the retina significantly suppressed retinal gliosis in vivo (Figs. 6 and 7). Because the expressed soluble TGF- $\beta$ receptor type II was shown to bind to recombinant TGF- $\beta$ protein (Sakamoto et al, 2000), the mechanism to inhibit GFAP up-regulation and retinal gliosis is therefore considered to most likely be caused by the competitive inhibition of TGF- $\beta$ ligand-receptor binding by expressed dominant-negative soluble TGF- $\beta$ receptor type II. The systemic blocking of TGF- $\beta$ signaling may have potential side effects on many other physiologic phenomena; however, in the previously published experiments and those presented here, the rats treated with a transient overexpression of soluble TGF- $\beta$ receptor type II appeared to be healthy and showed no apparent abnormalities microscopically.

Recent studies showed that Smads play a major role in these processes. Smads can be subdivided into three classes based on their functional properties, the receptor-regulated Smads (Smad1, 2, 3, 5, and 8), the common Smads (Smad4), and antagonistic Smads (Smad6 and 7). Upon activation of TGF receptor type II and I, Smad2 and/or Smad3 are transiently associated with the receptor and are directly phosphorylated by receptor kinases. The phosphorylated Smad then forms a heteromeric complex with Smad4, and this complex translocates from cytoplasm into nucleus, and, as a result, regulates the transcription of the 

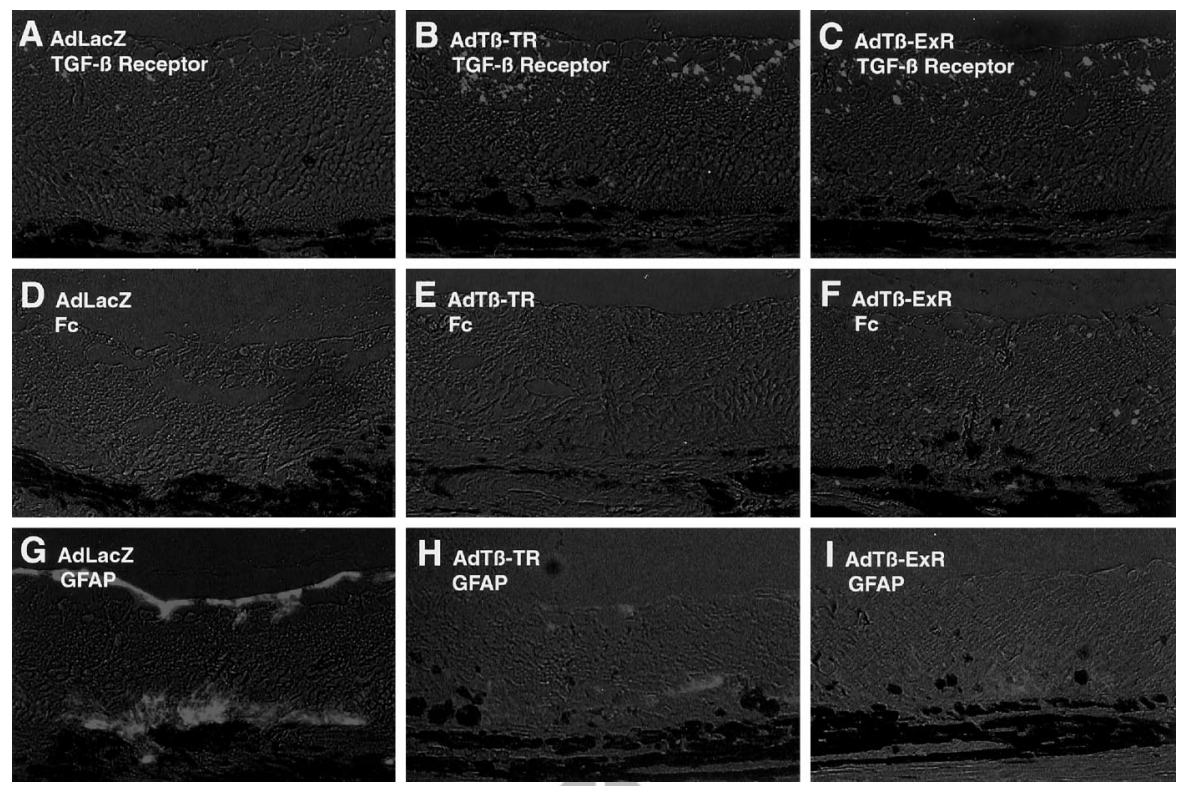

\section{Figure 6.}

Immunohistochemistry of retinas with photocoagulation. All Cy5-labeled fluorescent images (green) were composed with phase contrast images. Extracellular domain of TGF- $\beta$ type II receptor expression is shown (A to C). TGF- $\beta$ receptor-positive staining is seen mainly in the ganglion cell layer, inner plexiform layer, and inner nuclear layer (A, AdLacZ). An overexpression of the extracellular domain of TGF- $\beta$ receptor type II results in an increase in receptor-positive staining (B and $C)$. The tagged Fc portion of Human IgG expression is seen only in the AdT $\beta$-ExR group (F). Although GFAP staining is observed in all groups (G to I), the GFAP expression is remarkably suppressed in the groups overexpressed with a dominant-negative TGF- $\beta$ type II receptor (H and I). (Original magnification, $\times 200$.)

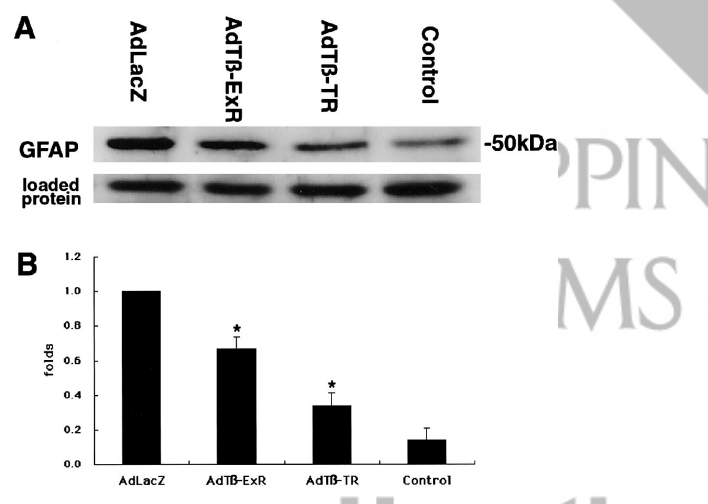

Figure 7.

GFAP expression in retinas after photocoagulation. A, AdLacZ and AdT $\beta$-ExR were administered intramuscularly, and AdT $\beta$-TR was injected into the vitreous space of the eyes. The control retina without PC shows a lower GFAP expression. Retinal photocoagulation shows a strong GFAP expression, and the expression is inhibited by AdT $\beta$-TR or AdT $\beta$-ExR, whereas AdLacZ showed no remarkable changes. Nonspecific staining was shown as a lane loading control. B, Semiquantitative data were generated by scanning film exposures of the gel using a densitometer. Three independent examinations were made and the results are expressed as a "fold" increase over the control GFAP expression (mean $\pm \mathrm{SD} ;{ }^{*} p<0.05$ ).

target genes. Thus phosphorylation of receptorregulated Smads or translocation of Smad4 is a suitable indicator of the intracellular signaling after these receptors. In the present study of retinal Müller cells, Smad4 immunoreactivity was diffusely observed among the cytosol without stimulation, whereas the nuclear accumulation of Smad4 was shown with TGF- $\beta$ stimulation, and the accumulation was effectively blocked by the conditioned medium containing the soluble TGF- $\beta$ receptor type II. These results indicate that the intracellular signaling of TGF- $\beta$ de- pend on Smads in Müller cells, and that a soluble type II receptor actually blocked TGF- $\beta$ signaling.

Interestingly, the intramuscular injection of AdT $\beta$ ExR resulted in a dramatic suppression of structural protein, GFAP, in immunohistochemistry (Fig. 6) and Western blotting (Fig. 7) in vivo. The inhibition of cup-regulated GFAP mRNA by AdT $\beta$-ExR supernatant in vitro was mild to moderate. Certainly, GFAP mRNA expression is moderately up-regulated by recombinant TGF- $\beta$ in vitro (Fig. 32.1 -fold). These results showed that the in vivo gene transfer of AdT $\beta$-ExR inhibited GFAP expression more effectively than that observed in vitro. There are two possible explanations for this phenomenon. One explanation is that mRNA and protein stability caused these differences, which result in a slight up-regulation of $m R N A$ and a large protein expression. GFAP is an intermediate filament protein, which is also known to markedly increase in reactive gliosis. The function of GFAP is thought to control the outgrowth of processes by glial cells, but its physiologic function remains elusive (Chen and Liem, 1994; McCall et al, 1996; Pekny et al, 1995; Weinstein et al, 1991). The moderate up-regulation of the protein in vitro supported this hypothesis (Fig. 1). Another explanation is that the inhibition of TGF- $\beta$ bioactivity can lead to the inhibition of following events in the retinal gliosis. TGF- $\beta$ can stimulate the migration of inflammatory cells and the expression of chemokines in such cells, which may cause an exacerbation of the subsequent inflammation or neovascularization. When the TGF- $\beta$ action was inhibited by AdT $\beta$-ExR, these negative events might be abolished, resulting in an effective inhibition of neural gliosis. 
In conclusion, the systemic administration of soluble TGF- $\beta$ receptor type II by adenovirus-mediated gene transfer (AdT $\beta$-ExR) effectively blocked the upregulation of GFAP and retinal gliosis after PC. These results give us a better understanding of the role of TGF- $\beta$ in vivo in retinal gliosis. The gene transfer of dominant negative truncated-type receptor is another potential method for blocking TGF- $\beta$ signaling, which was achieved by AdT $\beta$-TR and inhibited retinal gliosis in the present study. However, the intravitreous injection of adenovirus vector still has a negative effect on the retinal function (Sakamoto et al, 1998). Regarding the application of this above-described modality on humans, the transient transgene expression by replicant-deficient adenovirus-mediated gene therapy for the blockade of TGF- $\beta$ may be suitable for the limited therapeutic purpose of maintaining the retinal function for short periods after retinal injury or surgical recovery. The development of a delivery vector with a long, stable, and well-controllable expression may make it possible to eventually perform systemic transgene-therapy for such chronic or slowly progressive degenerative diseases as diabetic retinopathy or retinal degeneration.

\section{Materials and Methods}

All procedures conformed to the Association for Research in Vision and Ophthalmology (ARVO) statement for the Use of Animals in Ophthalmic and Vision Research.

\section{Replication-Defective Recombinant Adenoviruses}

Replication-defective adenoviral vectors expressing either a truncated human TGF- $\beta$ type II receptor (AdT $\beta$-TR) or $\beta$-galactosidase (AdLacZ) under a CA promoter comprising a cytomegalovirus enhancer and chicken $\beta$-actin promotor were prepared as previously described (Qi et al, 1999; Yamamoto et al, 1996). The truncated receptor was tagged with an influenza virus hemagglutinin epitope at its $\mathrm{N}$-terminal, as previously reported (Qi et al, 1999; Yamamoto et al, 1996). In the same way, a replication-defective adenoviral vector (AdT $\beta$-ExR) expressing an entire extracellular domain of the type II human TGF- $\beta$ receptor fused to the Fc portion of Human IgG, under the control of a CA promotor comprising a cytomegalovirus enhancer and a chicken $\beta$-actin promoter, was prepared by in vitro homologous recombination in 293 cells, as previously described (Sakamoto et al, 2000; Ueno et al, 2000; Yamamoto et al, 1996). This secreted soluble form of TGF- $\beta$ receptor type II has been shown to bind to recombinant TGF- $\beta$ protein, and block TGF- $\beta$ signaling in a dose-dependent manner (Ueno et al, 2000). The titer of the virus stock was assessed by a plaque formation assay using 293 cells and expressed in plaque-forming units.

\section{Isolation of Retinal Müller Cells}

Cultured bovine Müller cells were prepared as follows. Bovine eyes were obtained from a local slaughter- house and transported to the laboratory on ice. They were cut circumferentially, and the retinas were homogenized mechanically in DMEM (GIBCO BRL, Rockville, Maryland). The homogenate was digested in collagenase type II (Worthington Biochemical Corporation, Lakewood, New Jersey) for 45 minutes at $37^{\circ} \mathrm{C}$. The homogenate was subjected to centrifugation (1,000 $\times g, 2$ minutes), and the pellet was resuspended in DMEM. The homogenate was filtered over $106-\mu \mathrm{m}$ and $53-\mu \mathrm{m}$ sieves. The filtered homogenate was centrifuged (1,000 $\times g, 2$ minutes), resuspended in DMEM supplemented with $10 \%$ fetal bovine serum (FBS), and transferred to culture dishes coated with bovine fibronectin. The cultured medium was replaced twice a week. The cultured cells were confirmed as Müller cells by immunocytochemistry for GFAP.

\section{Inhibition of TGF- $\beta$ In Vitro in Cultured Müller Cells}

The conditioned medium containing soluble TGF- $\beta$ receptor type II was prepared and used in the following studies. These soluble receptors were shown to bind to TGF- $\beta$ and block the TGF- $\beta$ activity, as previously described (Sakamoto et al, 2000). The 293 E1 cells, which were derived from a human embryonic kidney cell line, were infected with adenoviral vector (AdT $\beta$-ExR) 10 multiplicity of infection (MOI), expressing an entire extracellular domain of the type II human TGF- $\beta$ receptor fused to the Fc portion of Human IgG, and the culture medium was removed. Then the 293 E1 cells were washed twice with PBS and incubated with serum-free DMEM for 14 hours. The culture medium was then collected and the cell debris was removed by centrifugation $(500 \times g, 10$ minutes.). The conditioned mediūm contained about 1,000 pM TGF- $\beta$ receptor-Fc protein, which was as much as 50 $\mathrm{ng} / \mathrm{ml}$ TGF- $\beta 1$ on a molar basis. The conditioned medium was collected and preincubated with $10 \%$ FCS and recombinant TGF- $\beta 1$ (R and D Systems, Minneapolis, Minnesota) at graded concentrations (3.0 ng TGF- $\beta$ per $10 \mathrm{ml}, 3 \mathrm{ml}, 1 \mathrm{ml}$ conditioned medium in $10 \mathrm{ml}$ totalmedium). The cultured medium from the 293 E1 cells infected with adenovirus (AdLacZ, $10 \mathrm{MOI}$ ) was used as a control. Cultured Müller cells were incubated with the mixed medium for 12 hours at $37^{\circ} \mathrm{C}$, and then the cells were harvested for RNA isolation and protein extraction.

\section{RT-PCR}

Total RNA was purified from cultured Müller cells using acid guanidine thiocyanate-phenol-chloroform extraction (AGPC) method. First-strand cDNA was synthesized using AMV reverse transcriptase (Boehringer Mannheim, Indianapolis, Indiana). The incubation time was 10 minutes at $25^{\circ} \mathrm{C}$ and 60 minutes at $42^{\circ} \mathrm{C}$. Reverse transcriptase was denatured at $99^{\circ} \mathrm{C}$ for 5 minutes before PCR amplification. Complementary DNA was subjected to PCR (GFAP, 32 cycles; $\beta$-actin, 24 cycles) in $20 \mu$ l volume containing $10 \mathrm{pmol}$ of primer pair and $2 \mu$ l of Light Cycler DNA Master SYBR Green (Boehringer Mannheim) using Light Cy- 
cler (Roche, Indianapolis, Indiana). Synthetic oligonucleotide primers based on the cDNA sequences of GFAP were (forward) 5'-AGGAGAACCGCATCACCATT-3' and (reverse) 5'-GACTCCTTAATGACCTCTCC-3'. The forward and reverse primer sets for $\beta$-actin were $5^{\prime}$-ACCACTGGAATGCGCTGTT-3' and 5'-GCTTCTCCTTGATGTCACGC-3', respectively. The PCR products were separated by electrophoresis on a $2 \%$ agarose gel and were stained with ethidium bromide. Semiquantitative data were generated by scanning film exposures of the gel using a densitometer (MacScope; Mitani, Fukui, Japan). Three independent examinations were made and the results are expressed as the "fold" increase over control GFAP mRNA expression (mean $\pm \mathrm{SD}$ ). Statistical analysis of values was performed by the unpaired Student's $t$ test; a $p$ value $<0.05$ was considered significant.

\section{Preparation of Protein Samples and Western Blot Analysis}

A Western blot analysis was performed with both cell lysates of cultured Müller cells and whole lysates of harvested total retina. Protein samples were separated by sodium dodecyl sulfate-polyacrylamide gel electrophoresis (SDS-PAGE), followed by electrophoretic transfer to nitrocellulose membranes. After blocking with skim milk, the blots were incubated overnight at $4^{\circ} \mathrm{C}$ with mouse anti-human monoclonal antibody specific for GFAP (1:2,000; Santa Cruz Biotechnology, Santa Cruz, California). After washing, the membranes were incubated with horseradish peroxidase-labeled goat-anti mouse antibody for 1 hour at room temperature. Visualization was performed using Amersham Phărmacia Biotech ECL detection system according to the manufacturer's protocol.

\section{Nuclear Translocation of Smad4 by TGF- $\beta$}

The bovine Müller cells were cultured on chamber slides (Lab-Tek, Naperville, Illinois) in DMEM with $10 \%$ fetal calf serum at $37^{\circ} \mathrm{C}$. Then medium was changed to the mixed serum containing TGF- $\beta(3.0 \mathrm{ng} / \mathrm{ml})$ and soluble TGF type II receptor, described previously. The cultured medium from the $293 \mathrm{E} 1$ cells infected with adenovirus (AdLacZ, $10 \mathrm{MOI}$ ) was used as a control. After 30 minutes of incubation, the cells were fixed in acetone for 5 minutes and washed in PBS. Anti-Smad4 antibody (Santa Cruz Biotechnology) was used at a 1:100 dilution for 1 hour. A nonimmune serum was used as a negative control. Cy5-labeled secondary antibody (Zymed Laboratories, San Francisco, California) was used at a dilution of 1:200 for 20 minutes. The cells were co-stained by propidium iodide (Molecular Probes, Eugene, Oregon) and observed by a fluorescence microscope.

\section{Inhibition of TGF- $\beta$ In Vivo in an Animal Model of Retinal Gliosis}

Brown Norway rats (Kyudo, Fukuoka, Japan), postnatal 8 weeks, were used in the following studies. The rats were anesthetized with an intraperitoneal injection of pentobarbital and their pupils were dilated with topical $1 \%$ tropicamide and $2.5 \%$ phenylephrine hydrochloride. The rats were divided into three groups; each animal of the following groups received the intramuscular injection (right femoral muscle) of either AdLacZ or AdT $\beta$-ExR $\left(0.2 \mathrm{ml}, 1 \times 10^{-8} \mathrm{pfu}\right)(n=6$ in each group). To see the direct inhibition of TGF- $\beta$ signaling, AdT $\beta$-TR $\left(0.05 \mathrm{ml}, 0.25 \times 10^{-8} \mathrm{pfu}\right)$ was injected into the vitreous using 30 -gauge needle by our previously described method (Sakamoto et al, 1998). Immediately after the injection, retinal PC was carried out at the following parameters: 8 spots per eye, Argon laser, a power of 50 to $100 \mathrm{~mJ}$, an exposure duration of $50 \mathrm{msec}$, and a spot size of 100 $\mu \mathrm{m}$ by our previously described method (Honda et al, 2000). The PC made circular white lesions in the retina without hemorrhage or bubble formation. The eyes were harvested 12 days after PC, and analyzed by immunohistochemistry and Western blotting. These soluble receptor proteins were shown to be redistributed in the serum and eyes, if AdT $\beta$-ExR was administered intramuscularly (Sakamoto et al, 2000).

\section{Histologic Examination}

Samples were fixed in 4\% paraformaldehyde, embedded in paraffin, deparaffinized in xylene, rehydrated in ethanol, and washed in PBS. Anti-TGF type II receptor polyclonal antibody (Santa Cruz Biotechnology) was used at a 1:200 dilution, and anti-human IgG antibody (Dako, Tokyo, Japan) was used at a 1:100 dilution, overnight. Anti-GFAP polyclonal antibody (Dako) was used at a 1:100 dilution, overnight. A nonimmune serum was used as a negative control. Cy5-labeled secondary antibody (Zymed Laboratories) was used at a dilution of 1:200 for 20 minutes. Sections were observed by fluorescent microscope (Olympus, Tokyo, Japan) and these fluorescent images were shown with phase-contrast images.

\section{Acknowledgements}

- We thank Dr. Shozo Shimokawa (Shimokawa Ophthalmological Clinic) for his financial support. We also thank Prof. Brian T. Quinn (Kyushu University) for editorial assistance.

\section{References}

Anderson DH, Guerin CJ, Hageman GS, Pfeffer BA, and Flanders KC (1995). Distribution of transforming growth factor-beta isoforms in the mammalian retina. $\mathrm{J}$ Neurosci Res 42:63-79.

Audouy S, Mallet J, Privat A, and Gimenez y Ribotta M (1999). Adenovirus-mediated suicide gene therapy in an in vitro model of reactive gliosis. Glia 25:293-303.

Bottner M, Krieglstein K, and Unsicker K (2000). The transforming growth factor-betas: Structure, signaling, and roles in nervous system development and functions. J Neurochem 75:2227-2240. 
Chen WJ and Liem RK (1994). The endless story of the glial fibrillary acidic protein. J Cell Sci 107:2299-2311.

da Cunha A, Jefferson JJ, Tyor WR, Glass JD, Jannotta FS, and Vitkovic $L$ (1993). Control of astrocytosis by interleukin-1 and transforming growth factor-beta 1 in human brain. Brain Res 631:39-45.

Dyer MA and Cepko CL (2000). Control of Muller glial cell proliferation and activation following retinal injury. Nat Neurosci 3:873-880.

Flanders KC, Ludecke G, Engels S, Cissel DS, Roberts AB, Kondaiah P, Lafyatis R, Sporn MB, and Unsicker K (1991). Localization and actions of transforming growth factor-beta $\mathrm{S}$ in the embryonic nervous system. Development 113:183191.

Hisatomi T, Sakamoto T, Murata T, Yamanaka I, Oshima Y, Hata $\mathrm{Y}$, Ishibashi T, Inomata H, Susin SA, and Kroemer G (2001). Relocalization of apoptosis-inducing factor in photoreceptor apoptosis induced by retinal detachment in vivo. Am J Pathol 158:1271-1278.

Honda M, Sakamoto T, Ishibashi T, Inomata $\mathrm{H}$, and Ueno $\mathrm{H}$ (2000). Experimental subretinal neovascularization is inhibited by adenovirus-mediated soluble VEGF/flt-1 receptor gene transfection: A role of VEGF and possible treatment for SRN in age-related macular degeneration. Gene Ther 7:978985 .

Ikeda T, Homma Y, Nisida K, Hirase K, Sotozono C, Kinoshita S, and Puro DG (1998). Expression of transforming growth factor-beta $s$ and their receptors by human retinal glial cells. Curr Eye Res 17:546-550.

Ishida K, Yoshimura N, Yoshida M, and Honda Y (1998). Upregulation of transforming growth factor-beta after panretinal photocoagulation. Invest Ophthalmol Vis Sci 39:801 807.

Laping NJ, Teter B, Nichols NR, Rozovsky I, and Finch CE (1994). Glial fibrillary acidic protein: Regulation by hormones, cytokines, and growth factors. Brain Pathol 4:259-275.

Lippa CF, Smith TW, and Flanders KC (1995). Transforming growth factor-beta: Neuronal and glial expression in CNS degenerative diseases. Neurodegeneration 4:425-432.

Logan A, Berry M, Gonzalez AM, Frautschy SA, Sporn MB, and Baird A (1994). Effects of transforming growth factor beta 1 on scar production in the injured central nervous system of the rat. Eur J Neurosci 6:355-363.

Logan A, Green J, Hunter A, Jackson R, and Berry M (1999). Inhibition of glial scarring in the injured rat brain by a recombinant human monoclonal antibody to transforming growth factor-beta2. Eur J Neurosci 11:2367-2374.

McCall MA, Gregg RG, Behringer RR, Brenner M, Delaney CL, Galbreath EJ, Zhang CL, Pearce RA, Chiu SY, and Messing A (1996). Targeted deletion in astrocyte intermediate filament (GFAP) alters neuronal physiology. Proc Natl Acad Sci USA 93:6361-6366.

Nakao A, Imamura T, Souchelnytskyi S, Kawabata M, Ishisaki A, Oeda E, Tamaki K, Hanai J, Heldin CH, Miyazono K, and ten Dijke P (1997). TGF-beta receptor-mediated signalling through Smad2, Smad3 and Smad4. Embo J 16:5353-5362.

Ogata N, Yamamoto C, Miyashiro M, Yamada H, Matsushima $M$, and Uyama M (1997). Expression of transforming growth factor-beta mRNA in experimental choroidal neovascularization. Curr Eye Res 16:9-18.
Pekny $\mathrm{M}$, Leveen $\mathrm{P}$, Pekna $\mathrm{M}$, Eliasson $\mathrm{C}$, Berthold $\mathrm{CH}$, Westermark B, and Betsholtz C (1995). Mice lacking glial fibrillary acidic protein display astrocytes devoid of intermediate filaments but develop and reproduce normally. Embo $\mathrm{J}$ 14:1590-1598.

Pfeffer BA, Flanders KC, Guerin CJ, Danielpour D, and Anderson DH (1994). Transforming growth factor beta 2 is the predominant isoform in the neural retina, retinal pigment epithelium-choroid and vitreous of the monkey eye. Exp Eye Res 59:323-333.

Qi Z, Atsuchi N, Ooshima A, Takeshita A, and Ueno H (1999). Blockade of type beta transforming growth factor signaling prevents liver fibrosis and dysfunction in the rat. Proc Natl Acad Sci USA 96:2345-2349.

Reilly JF, Maher PA, and Kumari VG (1998). Regulation of astrocyte GFAP expression by TGF-beta1 and FGF-2. Glia 22:202-210.

Ridet JL, Malhotra SK, Privat A, and Gage FH (1997). Reactive astrocytes: Cellular and molecular cues to biological function. Trends Neurosci 20:570-577.

Sakamoto T, Ueno H, Goto Y, Oshima Y, Ishibashi T, and Inomata $H$ (1998). A vitrectomy improves the transfection efficiency of adenoviral vector-mediated gene transfer to Muller cells. Gene Ther 5:1088-1097.

Sakamoto $\mathrm{T}$, Ueno $\mathrm{H}$, Sonoda K, Hisatomi T, Shimizu K, Ohashi H, and Inomata H (2000). Blockade of TGF-beta by in vivo gene transfer of a soluble TGF-beta type II receptor in the muscle inhibits corneal opacification, edema and angiogenesis. Gene Ther 7:1915-1924.

Streit WJ, Walter SA, and Pennell NA (1999). Reactive microgliosis. Prog Neurobiol 57:563-581.

Taomoto M, Nambu H, Senzaki H, Shikata N, Oishi Y, Fujii T, Miki H, Uyama M, and Tsubura A (1998). Retinal degeneration induced by $\mathrm{N}$-methyl- $\mathrm{N}$-nitrosourea in Syrian golden hamsters. Graefes Arch Clin Exp Ophthalmol 236:688-695. Ueno H, Sakamoto T, Nakamura T, Qi Z, Astuchi N, Takeshita A, Shimizu K, and Ohashi H (2000). A soluble transforming growth factor beta receptor expressed in muscle prevents liver fibrogenesis and dysfunction in rats. Hum Gene Ther $11: 33-42$

Unsicker K (2000). Transforming growth factor-beta. Eur J Biochem 267:6953.

Weinstein DE, Shelanski ML, and Liem RK (1991). Suppression by antisense mRNA demonstrates a requirement for the glial fibrillary acidic protein in the formation of stable astrocytic processes in response to neurons. J Cell Biol 112:12051213.

Yamamoto C, Ogata N, Yi X, Takahashi K, Miyashiro M, Yamada H, Uyama M, and Matsuzaki K (1998). Immunolocalization of transforming growth factor beta during wound repair in rat retina after laser photocoagulation. Graefes Arch Clin Exp Ophthalmol 236:41-46.

Yamamoto H, Ueno H, Ooshima A, and Takeshita A (1996). Adenovirus-mediated transfer of a truncated transforming growth factor-beta (TGF-beta) type II receptor completely and specifically abolishes diverse signaling by TGF-beta in vascular wall cells in primary culture. J Biol Chem 271: 16253-16259. 